\title{
Analysis of landings of Indian mackerel during the period 2014 to 2018 at Junglighat fish landing centre, South Andaman, India
}

1*PRIST University, THANJAVUR, INDIA

${ }^{2}$ Central Island Agricultural Research Institute, PORT BLAIR, INDIA

${ }^{3}$ Department of Zoology, JNRM, (PORT BLAIR) INDIA

${ }^{*}$ Corresponding Author Email: kamuthy@gmail.com

Received : 18.09.2019; Accepted : 04.11.2019

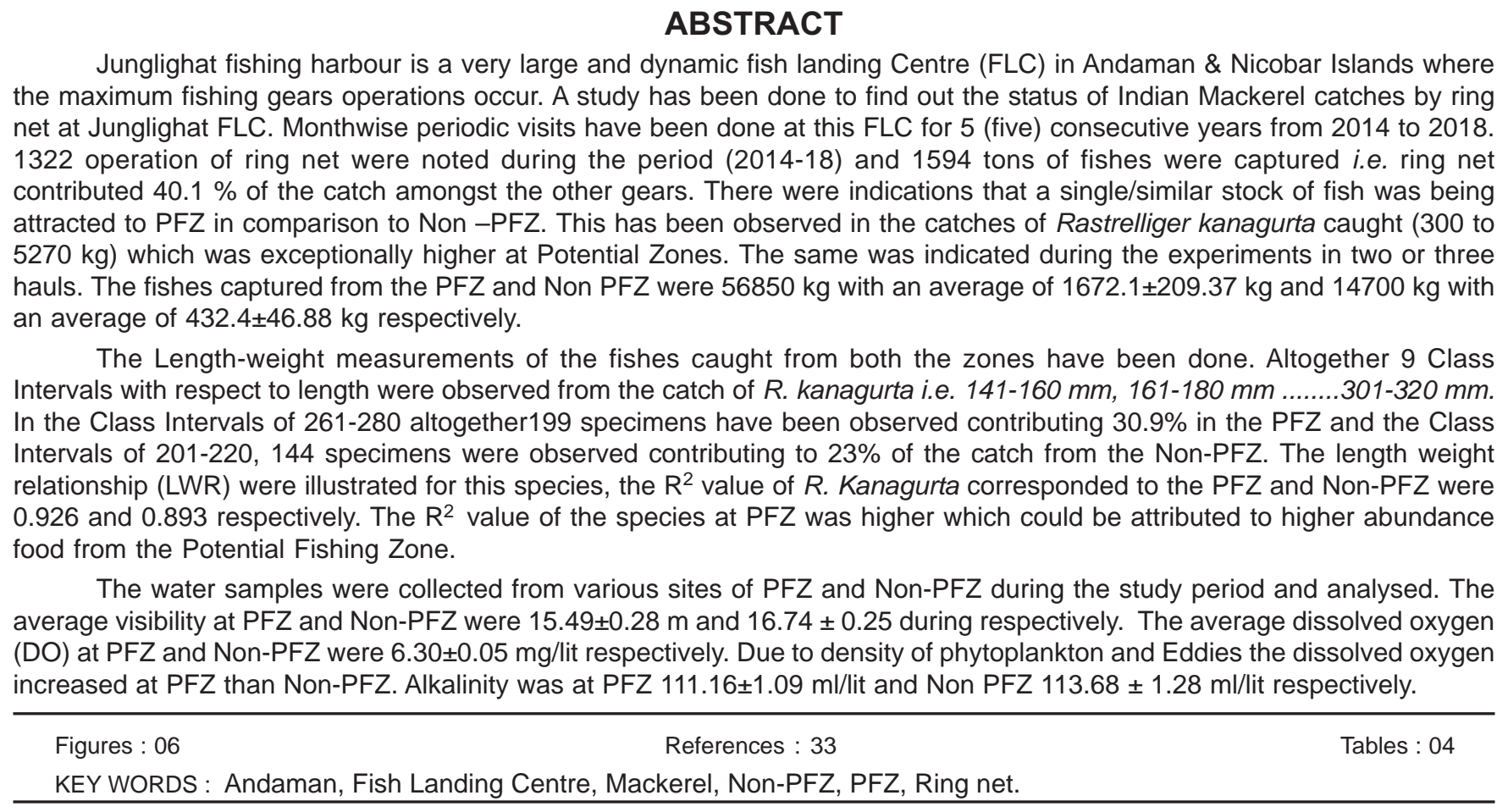

\section{Introduction}

Andaman and Nicobar Islands (ANI) situated between60 45' N and 130 41' N and 920 12' E and 93057' $\mathrm{E}$, has 0.6 million sq $\mathrm{km}$ of Exclusive Economic Zone (EEZ) and $1192 \mathrm{~km}$ of coastline. The continental shelf around the Islands is very narrow and is estimated to be around $35000 \mathrm{sq} \mathrm{km}{ }^{4}$. ANI is unique in possessing high magnitude of harvestable fishery resources of more than 1.48 lakh tonne per annum ${ }^{9}$. According to some workers $^{17}$, ANI have an estimated fisheries potential of 2.4 lakh tonnes/ annum. But, the fish harvest has always been far below the maximum sustainable yield with an average harvest of around 30,000 tonnes for the last few decades $^{9}$. The coastal waters surrounding the archipelago of the ANI located in the Bay of Bengal, account for about $28 \%$ of India's Exclusive Economic Zone, while the islands themselves make up $24 \%$ of the Indian coastline. The harvesting of Indian Mackerel is occurring in ANI throughout the year but sometimes due to inclement weather condition like cyclone, heavy rain, heavy waves, earthquake, tsunami etc., the fishermen would not venture into the sea for fishing. Mackerel recede from coastal 
TABLE-1: Fish landing through the Gear, Ring net (purse seine) at Junglighat FLC

\begin{tabular}{|l|c|c|c|c|c|c|c|}
\hline Ring net / Years & $\mathbf{2 0 1 4}$ & $\mathbf{2 0 1 5}$ & $\mathbf{2 0 1 6}$ & $\mathbf{2 0 1 7}$ & $\mathbf{2 0 1 8}$ & Total & Ave/ year \\
\hline Number of FLC visits & 177 & 129 & 137 & 136 & 113 & 692 & $138.4 \pm 10.56$ \\
\hline Number of operations & 289 & 266 & 287 & 238 & 242 & 1322 & $264.4 \pm 10.76$ \\
\hline $\begin{array}{l}\text { Total catch } \\
\text { (in tonnes) }\end{array}$ & 395.56 & 311.76 & 321.78 & 305.10 & 260.00 & 1594.19 & $218.84 \pm 21.90$ \\
\hline $\begin{array}{l}\text { Mackerel landed } \\
\text { (in tonnes) }\end{array}$ & 208.37 & 119.92 & 172.75 & 169.12 & 152.00 & 822.16 & $164.43 \pm 14.42$ \\
\hline
\end{tabular}

waters during the South West monsoon period for the purpose of spawning. It is believed that the fish after spawning do not permanently retire to deep sea, but come back to Coastal waters and their spawning ground are not very far from the coast.

The mackerel fisheries are mainly composed of 3 species, Rastrelliger kanagurta, Rastrelliger brachysoma, and Rastrelliger faughuni ${ }^{3,8}$. The Indian mackerel Rastrelliger kanagurta is a pelagic fish which move in separate shoals with different size group that is widely distributed in the Indo-Pacific region. It is a plankton feeder, feeding to a great extent on zooplankton and comparatively to a lesser extent on the phytoplankton.It has been variously classified as a planktonivore/ omnivore with varied diet composition (diatoms, dinoflagellates,

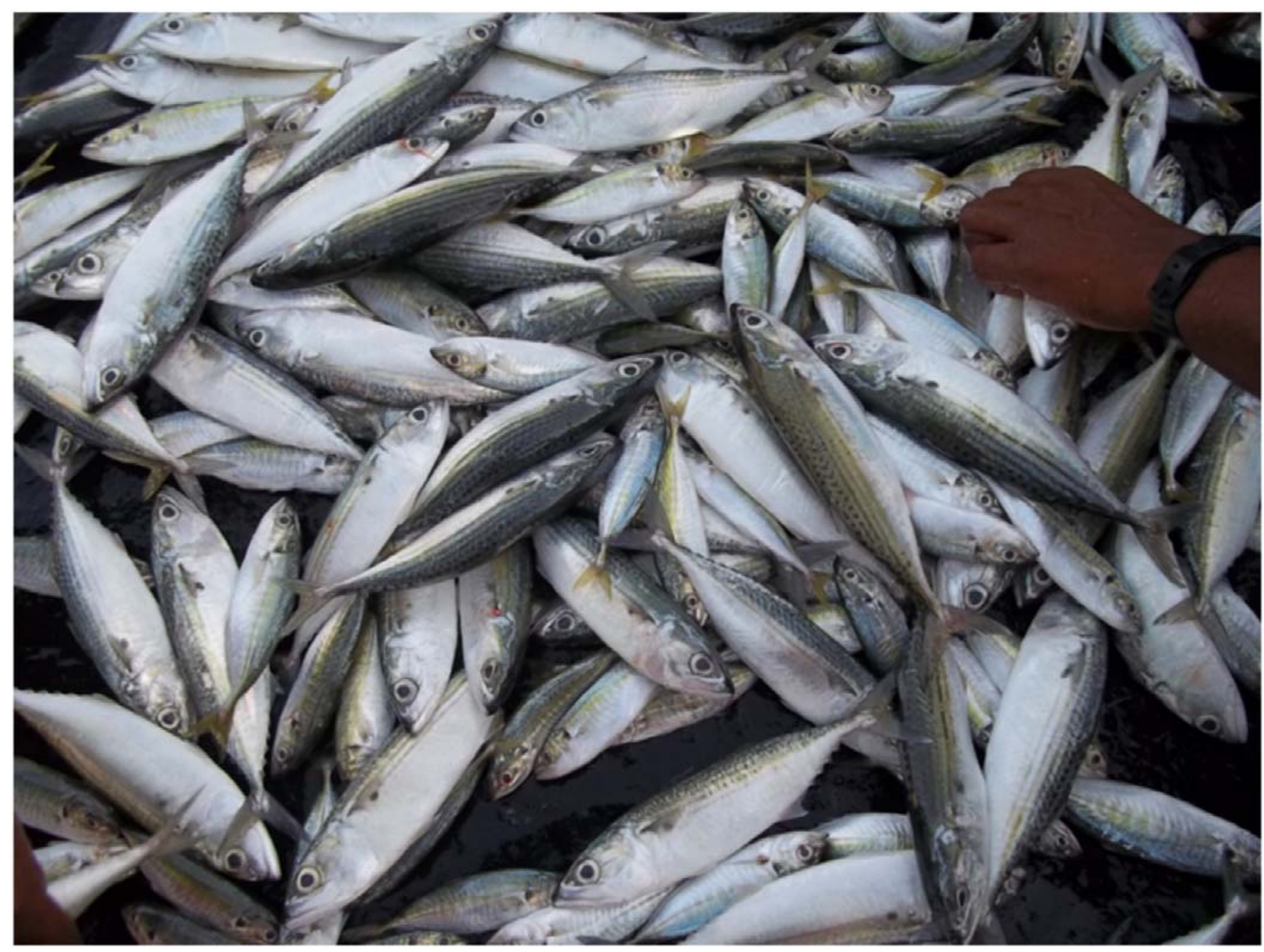

Fig.1: Indian Mackerel landing at Junglighat FLC, Port Blair, Andaman 
copepods, crustaceans and occasionally fish and sand particles) recorded by researchers in various fishery centres along the Indian coast ${ }^{32}$. The fish $R$. kanagurta is very important as food fish and is commonly used in South-East Asian cuisine. Currently the Indian Mackerel fish is widespread in the Indo-West Pacific from South Africa, Seychelles and Red Sea east through Indonesia and off northern Australia to Melanesia, Micronesia, Samoa, China and the Ryukyu Islands.

The Indian mackerel $R$. kanagurtais a major source of bait for the hand line and long line fishery, and also for human consumption in these Islands. The fishery is entirely dependent on schoolsmigrating inshore and the magnitude of the landings depends upon the availability of schools. The $R$. kanagurta is also well known to occur all the east and west coast of India including Andaman Sea in the inshore waters upto 10 - 30 meters which is highly exploited in Indian Coast. The commercial fishery begins to exploit mackerel from about a size of $18 \mathrm{~cm}$, which they attain within six months. Fish below this size are also caught in good numbers in some places. About 80-90\% of fish in the commercial catch comes from size below $22 \mathrm{~cm}$., which they attain in the first year of its life. The size groups above $22 \mathrm{~cm}$, contribute a small portion in the commercial catch. The bulk of the landings to the extent of about $80 \%$ come from the west coast centres, the chief among them being Quilon, Allepey, Cochin, Calicut, Tellicherry, Malpe, Karwar and Malwan. The fishery in general extends on the West Coast from Cape Comorin to Ratnagiri. On the East Coast spordic catches occur near Mandapam, Nagapattinam, Chennai, Kakinada, Visakhapatnam and some parts of Odisha coast.

\section{Review of Literature}

Schools of sardines, mackerel, skipjack and other varieties of fishes have been very frequently sighted around the islands, which provide much scope for purse seine operations and also comprised as highly economic varieties $^{21}$. Ninety percentage of the world mackerel production is contributed by India and fishes are of great domestic demand consumed both in fresh and cured conditions ${ }^{1}$. The annual landings of Indian mackerel along the Indian coast are about 2, 78, 495 tonnes, 1, 70, 297 tonnes and 1, 99, 880 tonnes during the years 2011, 2012 and 2013 respectively ${ }^{3.8}$. The production of mackerel in Andaman ranged between 806 to 1,955 t during 1989 '99. The Indian mackerel Rastrelliger kanagurta (Fig. 1) constitutes a prominent group in both the Arabian Sea as well as in Bay of Bengal ${ }^{15}$. The maximum catch of 1,955 tonnes was recorded in 1992 forming about $7.7 \%$

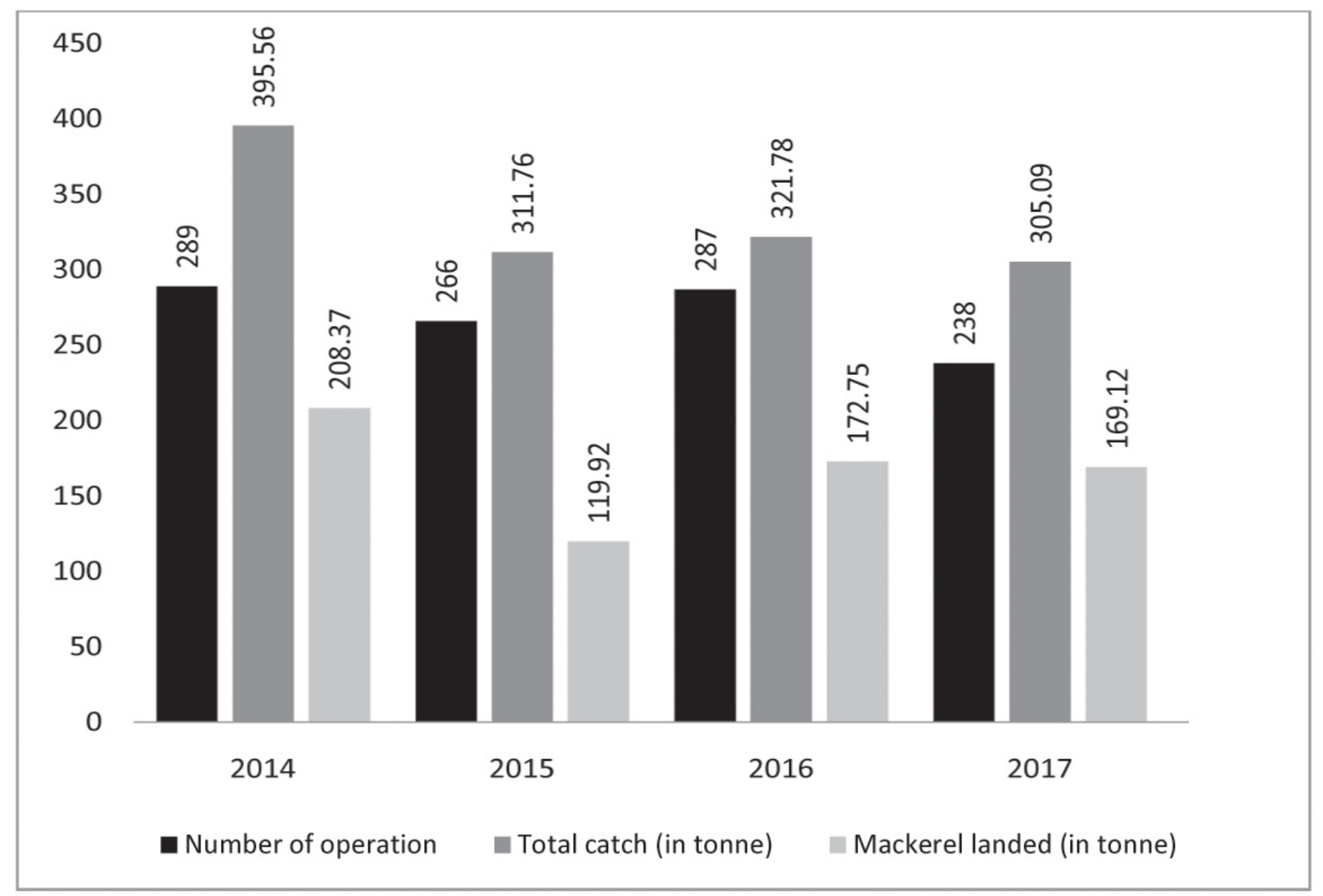

Fig. 2 : Diagram showing the boat operation and catch of $R$. kanagurta 
TABLE -2 : Month-wise Ring net operation and catch of $R$. kanagurta during 2014-18

\begin{tabular}{|l|c|c|c|c|l|}
\hline 2014-18 & \multicolumn{2}{|c|}{ Boat operation (in nos) } & \multicolumn{2}{l|}{ Fish catch (in tons) } & Remarks \\
\hline Months & Total & Average & Total & Average & \\
\hline January & 80 & $16.00 \pm 3.66$ & 37.49 & $7.50 \pm 2.40$ & \\
\hline February & 114 & $22.80 \pm 2.42$ & 66.63 & $13.33 \pm 1.90$ & \\
\hline March & 94 & $18.80 \pm 3.29$ & 36.49 & $7.30 \pm 1.71$ & Minimum catch \\
\hline April & 97 & $19.40 \pm 2.50$ & 68.29 & $13.66 \pm 3.23$ & \\
\hline May & 113 & $22.60 \pm 1.81$ & 81.95 & $16.39 \pm 2.99$ & \\
\hline June & 124 & $24.80 \pm 6.53$ & 80.43 & $16.09 \pm 6.47$ & \\
\hline July & 165 & $33.00 \pm 2.97$ & 121.32 & $24.26 \pm 7.44$ & Maximum catch \\
\hline August & 132 & $26.40 \pm 3.53$ & 75.70 & $15.14 \pm 1.98$ & \\
\hline September & 119 & $23.80 \pm 2.69$ & 74.60 & $14.92 \pm 3.11$ & \\
\hline October & 91 & $18.20 \pm 2.13$ & 65.57 & $13.11 \pm 0.61$ & \\
\hline November & 100 & $20.00 \pm 4.16$ & 60.06 & $12.01 \pm 2.26$ & \\
\hline December & 93 & $18.60 \pm 2.94$ & 53.63 & $10.73 \pm 2.52$ & \\
\hline
\end{tabular}

of the total fish landings and the major fishing season being from March to June and September to October and is best caught in the gill nets and boat seines (seine nets) ${ }^{19}$.

Sea Surface Temperature (SST) is the most easily observed environmental parameter and is quite often correlated with the availability of fish, especially pelagic fish. Many pelagic species are known to concentrate at current boundaries especially in areas with sharp horizontal temperature gradients. Usually, chlorophyll and SST images are expected to reveal common gradients due to inverse correlation between these two parameters ${ }^{25}$. Recent reports indicate that climate change induced variations in the marine environment such as SST have impacted the mackerel and sardine stocks leading to the northward extension of their distribution ranges, resulting in development of new fisheries targeting mackerel especially along the northwest coast of India 5 .

Monitoring the above mentioned parameters in space and time is time-consuming and prohibitively expensive and a real time picture of any one of these parameters or a combination of the above becomes almost impossible. Indirect methods of monitoring selected parameters such as SST and phytoplankton pigments
(Chlorophyll-a) at sea surface from satellites are found to be very ideal, as it provides high repetivity and large special coverage (INCOIS). Indian Remote Sensing Satellite P4 Ocean Colour Monitor (IRS P4 OCM) derived chlorophyll concentration and National Oceanographic Aerospace Administration Advanced Very High ResolutionRadiometer (NOAA AVHRR) derived Sea Surface Temperature (SST) images have been used to characterise the relationship between biological and physical variables in coastal waters and it was observed that both chlorophyll concentration and SST were inversely correlated $^{29}$. The relationship between these two parameters was estimated by a clustering technique called ARNONE and the matching features were selected for generating integrated PFZ forecasts from composite images on the basis of latitude and longitude ${ }^{28,23}$.

The length-weight relationships (LWR) of fishes are important in fisheries biology because they allow the estimation of the average weight of the fish of a given length group by establishing a mathematical relation between the two ${ }^{20}$. Like any other morphometric characters, the LWR can be used as a character for the differentiation of taxonomic units and the relationship changes with the various developmental events in life such 


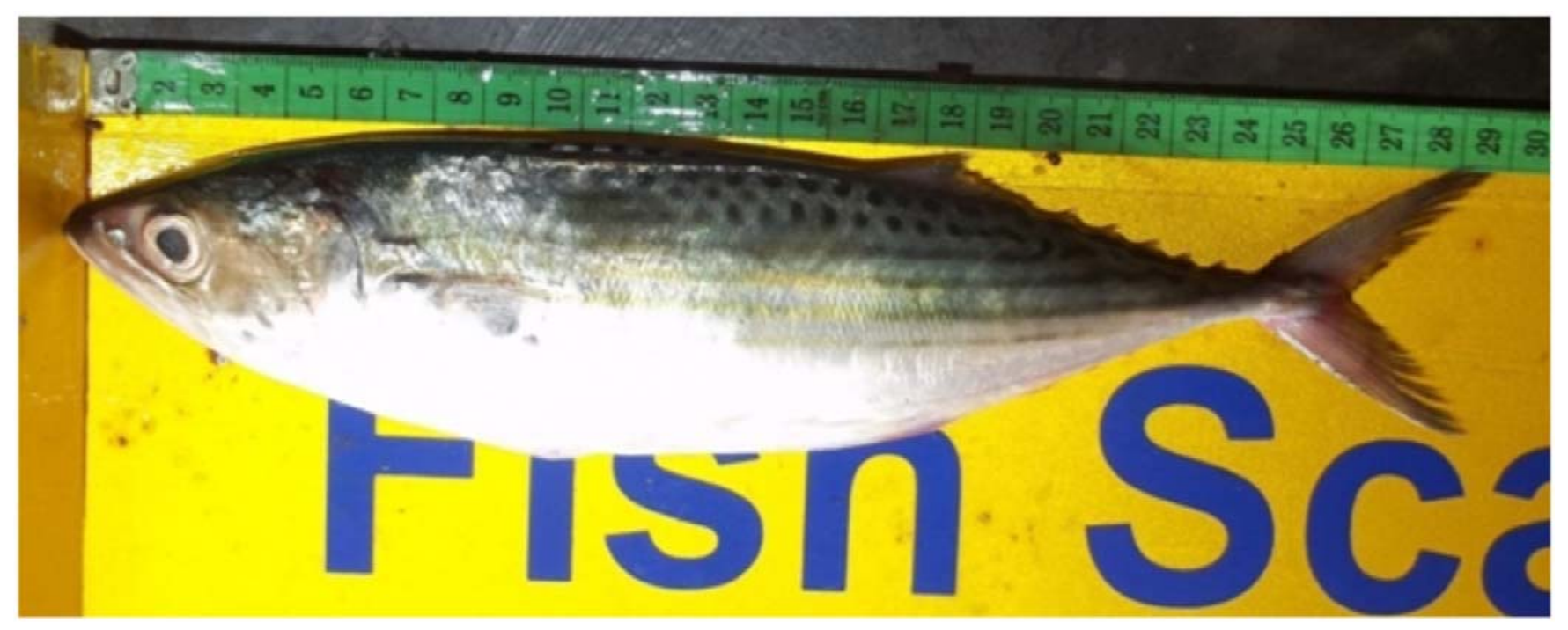

Fig. 3 : Indian Mackerel (Rastrelliger kanagurta)

as metamorphosis, growth and on-set of maturity ${ }^{31}$. Besides this, the LWR can also be used in setting yield equations for estimating the number of fish landed and comparing the population in space and time ${ }^{6}$. LWR parameters ( $a$ and $b$ ) are useful in fisheries science in many ways :to estimate weight of individual fish from its length, to calculate condition indices, to compare life history and morphology of populations belonging to different regions ${ }^{24}$ and to study ontogenetic allometric changes $^{30}$. Furthermore the empirical relationship between the length and weight of the fish enhances the knowledge of the natural history of commercially important fish species, thus making the conservation possible.

PFZ advisories generated from satellite retrieved SST and Chlorophyll were found more beneficial to artisanal, motorized and small mechanized sector fishermen engaged in pelagic fishing activities such as ring seining, gill netting etc., thereby reducing the searching time which in turn result in the saving of valuable fuel oil and also human effort. The EEZ around Andaman and Nicobar Islands is spread between lat 14 to $5 \mathrm{~N}$ and Long 89 to $95 \mathrm{E}$. The annual average of Chl-a in the Andaman Sea was $7.8 \mathrm{mg} \mathrm{m}^{-2}$ or $4.38 \times 10^{3}$ tones. The PFZ advisories with satellite imagery maps were received from Indian National Centre for Ocean Information Services (INCOIS), Hyderabad from time to time. Remotely-sensed oceanic features translated as PFZ forecasts in near real time indicating the likely availability of fish stocks for the next 2-3 days were disseminated by Indian National Centre for Ocean Information Services (INCOIS) to about 225 nodes for operational use ${ }^{22}$. After the receipt of the satellite picture the same was printed and disseminated amongst the fishermen to enhance their fish catch by indicating with lat \& long and reducing the scouting time. There are indications that a single/similar stock of fish is being attracted to PFZ in comparison to Non -PFZ. Junglighat fishing harbour is a very large and dynamic fish landing Centre (FLC) in Andaman \& Nicobar Islands where the maximum fishing gears operations occur. Month wise periodic visits were carried out at this FLC for 5 (five) consecutive years from 2014 to 2018 and data with respect to the monthly and annual estimates of catches were calculated.

The Ring net is the main gear to capture the pelagic fishes like Scombrids, Sardines, Carangids, etc in large quantity (i.e 0.5 to 5 ton/ boat) from this FLC. The location of fishing grounds of ring netters are falling around the

TABLE-3: Validation conducted on Ring net operation In and Out of PFZ during the year 2014 to 2018.

\begin{tabular}{|c|c|c|c|c|c|c|}
\hline Year & 2014 & 2015 & 2016 & 2017 & 2018 & Total \\
\hline Number of Validation conducted in PFZ & 5 & 3 & 6 & 8 & 11 & 33 \\
\hline Fish catches in PFZ (in kg) & 4200 & 2500 & 10200 & 7790 & 32160 & 56850 \\
\hline Number of Validation conducted in Non-PFZ & 5 & 3 & 6 & 8 & 11 & 33 \\
\hline Fish catches in Non-PFZ (in kg) & 1680 & 700 & 2900 & 1670 & 7750 & 14700 \\
\hline
\end{tabular}




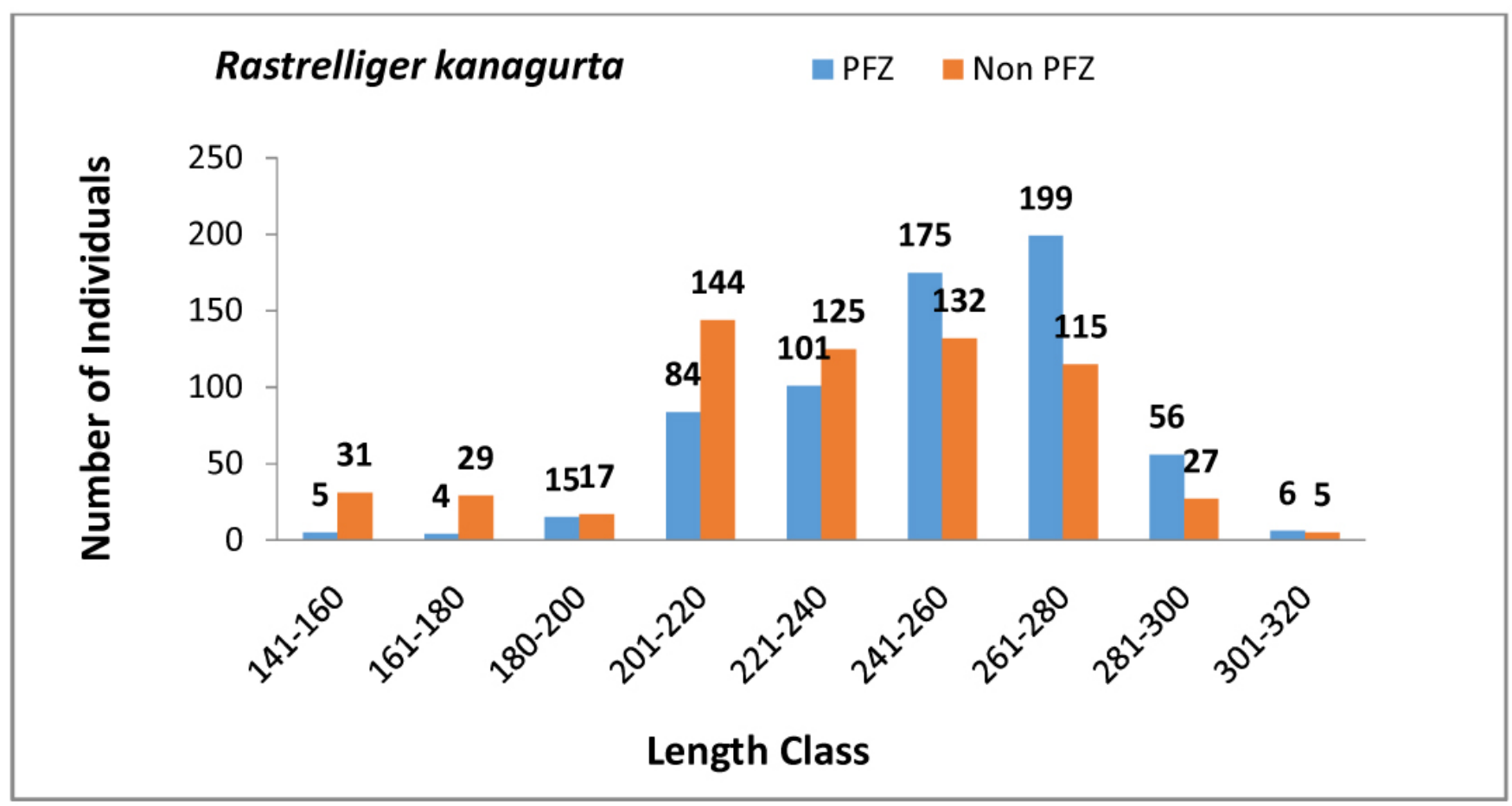

Fig. 4 : Length frequency of Rastrelliger kanagurta

South, Middle and North Andaman Islands and the maximum visited grounds were Coastal area of Havelock, Chidiatappu, Rutland, Baratang, Shoal Bay, Colinpur, Wandoor etc. The landing data of all the fishes were collected and Mackerel landings were analysed separately during the periods of visit. While the collection of data, the further information viz location of fishing area, observation of water colour, area of the depth, visibility of water, wind direction and speed, etc., were also collected.

Some workers ${ }^{33}$ reported that the average length frequency distribution of mackerel along the west coast of India is constituted by size group $110-150 \mathrm{~mm}$ with mode at $145 \mathrm{~mm}$, while along the east coast, larger size groups of $175-215 \mathrm{~mm}$ with modal size $195 \mathrm{~mm}$ were recorded. The life span of mackerel is believed to be about two years and growth is very fast especially in the juvenile stages, with fishes reaching a length of about $190 \mathrm{~mm}$ by the end of first yearr ${ }^{11}$.

\section{Materials and Methods}

The water quality parameters of fishing areas also had been carried out in few places to identify the supporting parameters for availability of fishes in particular areas or locations during controlled experiments. The relationships between length and weight of fish were analyzed by measuring length and weight of fish specimens collected from the study areas included in and out of PFZ.Validation for PFZ advisories also have been carried out during the study period for ring net operation and differentiation of fish catch, Length-weight relationships and water quality parameters of PFZ and Non PFZ have been analysed. Identification of Potential Fishing Zones (PFZ) involves an understanding of oceanic processes and interaction of hydro-biological parameters ${ }^{10}$.

The landing centre visits have been carried out at Junglighat Fish Landing Centre during the study period i.e. five consecutive years from 2014 to 2018. The maximum visits were carried out during the year 2014 (177) and the minimum visits were done during the year 2018 (113). Altogether 692 numbers of visit had been occurred with an average of $138.4 \pm 10.56$ per year (Table-1).

The other data like number of ring net operations, fish catch, catches of Indian Mackerel per boat etc., have been collected during the visiting period for consecutive four years i.e. 2014 - 2018. The collected data were analysed monthwise and the yearwise, ring net operations during the above mentioned period. Altogether 1322 operations of ring net were noted during the study period (2014-18) with an average of $264.40 \pm 10.76$ / year.

\section{Result and Discussion}

There were 1594 tons of fishes captured during the period i.e. ring net contributed $40.1 \%$ of the catch amongst the other gears. Amongst the pelagic fish landings, the Indian Mackerel (Rastrelliger kanagurta) contributes to more than $50 \%$ i.e. 822.15 tons during the 5 years with an average of $164.430 \pm 14.42$ tons/year and also found that the maximum quantity captured during 
TABLE - 4 : Hydrographical parameters in and outside of PFZ during the study period:

\begin{tabular}{|l|c|c|c|c|}
\hline \multirow{2}{*}{ Parameters } & \multicolumn{2}{|c|}{ PFZ } & \multicolumn{2}{c|}{ Non PFZ } \\
\cline { 2 - 5 } & Range & Average & Range & Average \\
\hline Air Temperature & $28.00-32.00$ & $30.62 \pm 0.09$ & $27.00-32.00$ & $30.19 \pm 0.09$ \\
\hline Water temperature & $28.00-30.50$ & $29.13 \pm 0.05$ & $27.50-30.96$ & $29.17 \pm 0.06$ \\
\hline pH & $7.13-8.30$ & $8.00 \pm 0.02$ & $7.60-8.40$ & $8.05 \pm 0.01$ \\
\hline Secch Disk visibility & $6.00-22.00$ & $15.49 \pm 0.28$ & $7.00-23.10$ & $16.74 \pm 0.25$ \\
\hline Dissolved Oxygen (mg/lit) & $4.44-6.94$ & $6.30 \pm 0.05$ & $4.70-6.80$ & $5.95 \pm 0.06$ \\
\hline Salinity (ppt) & $28.50-35.00$ & $32.67 \pm 0.12$ & $28.50-35.00$ & $32.69 \pm 0.13$ \\
\hline Alkalinity (mg/lit) & $80.00-125.00$ & $111.16 \pm 1.09$ & $88.00-144.00$ & $113.68 \pm 1.28$ \\
\hline
\end{tabular}

2014 i.e. 208.37 tons and minimum quantity was captured during 2015 i.e. 119.92 tons (Fig. 2). According to the $\mathrm{FSI}^{13}$ the marine fishery in the ANI is dominated by pelagic catches, which comprise about $60 \%$ of the total catch. Gillnet (27\%), hand line (54\%), long line (5\%), and ring net/seine (1\%) are the major types of fishing gears used in the Andaman fishery.

The mackerel fishery along the Indian coast is essentially comprised of a single species, $R$. kanagurta although two other species namely, R.brachysoma (Bleeker,1851) in Andaman seas ${ }^{18}$ and R.faughni (Matsui, 1967) along the east coast of India ${ }^{14}$ are also recorded to occur in stray numbers. Indian Mackerel Rastrelliger kanagurta is highly exploited in these Islands and some of the harvested catch is exported to mainland, India.

Boat operations observed the maximum numbers during the month of July (165) with an average of $33.00 \pm 2.97$ nos. and minimum numbers observed during January (80) with an average of $16.00 \pm 3.66$ nos. Analyses of monthwise catch during the study period have been carried out with the standard errors, it was found that the maximum catch of $R$. kanagurta was observed during the month of July for study period i.e. 121.31 tons with an average of $24.26 \pm 7.44$ tons/ year and the minimum catch was noted during February for study period i.e. 36.49 tons with an average of $7.50 \pm 2.40$ tons/ year (Table -2).

\section{Validations for PFZ Advisories:}

After the receipt of the satellite picture the same is printed and disseminated amongst the fishermen to enhance their fish catch by indicating with lat \& long and reducing the scouting time. There are indications that $a$ single/similar stock of fish is being attracted to PFZ in comparison to Non-PFZ. This has been observed in the catches of Rastrelliger kanagurta caught (300 to 5270 $\mathrm{kg}$ ) which is exceptionally higher at Potential Zones. The same is indicated during the experiments in two or three hauls. The fishes captured from the PFZ and Non PFZ were $56850 \mathrm{~kg}$ with an average of $1672.1 \pm 209.37 \mathrm{~kg}$ and $14700 \mathrm{~kg}$ with an average of $432.4 \pm 46.88 \mathrm{~kg}$ respectively (Table 3). Validation of PFZ forecasts have inferred substantial increase in fish catch along northwest coast of Gujarat $26,27,22,12$, and all over the country ${ }^{7}$. The annual exploitable fisheries of Andaman and Nicobar Islands are estimated to be 1.48 lakh t of which a meagre $22 \%$ is harvested currently. Potential Fishing Zone (PFZ) forecasts based on remotely sensed chlorophyll concentration and sea surface temperature were applied for harvesting the unexploited marine fishery resources ${ }^{17}$. Identification of Potential Fishing Zones (PFZ) involves an understanding of oceanic processes and interaction of hydro-biological parameters ${ }^{10}$. Each fishing operation executes a unique harvesting technique and thus vary in terms of number of crew, duration of fishing, depth of operation, type of gear deployed and species/quantity of fish harvested ${ }^{22}$. From the quantitative results of the fishing operations done by identical vessels simultaneously within and outside PFZ area, it was concluded that the average income generated by vessels operating in the PFZ areas were considerably higher than vessels operating in non PFZ areas. Fishing expenses were also comparatively less for vessels which operated within PFZ.

\section{Length frequency of Rastrelliger kanagurta at PFZ} and Non- PFZ : 


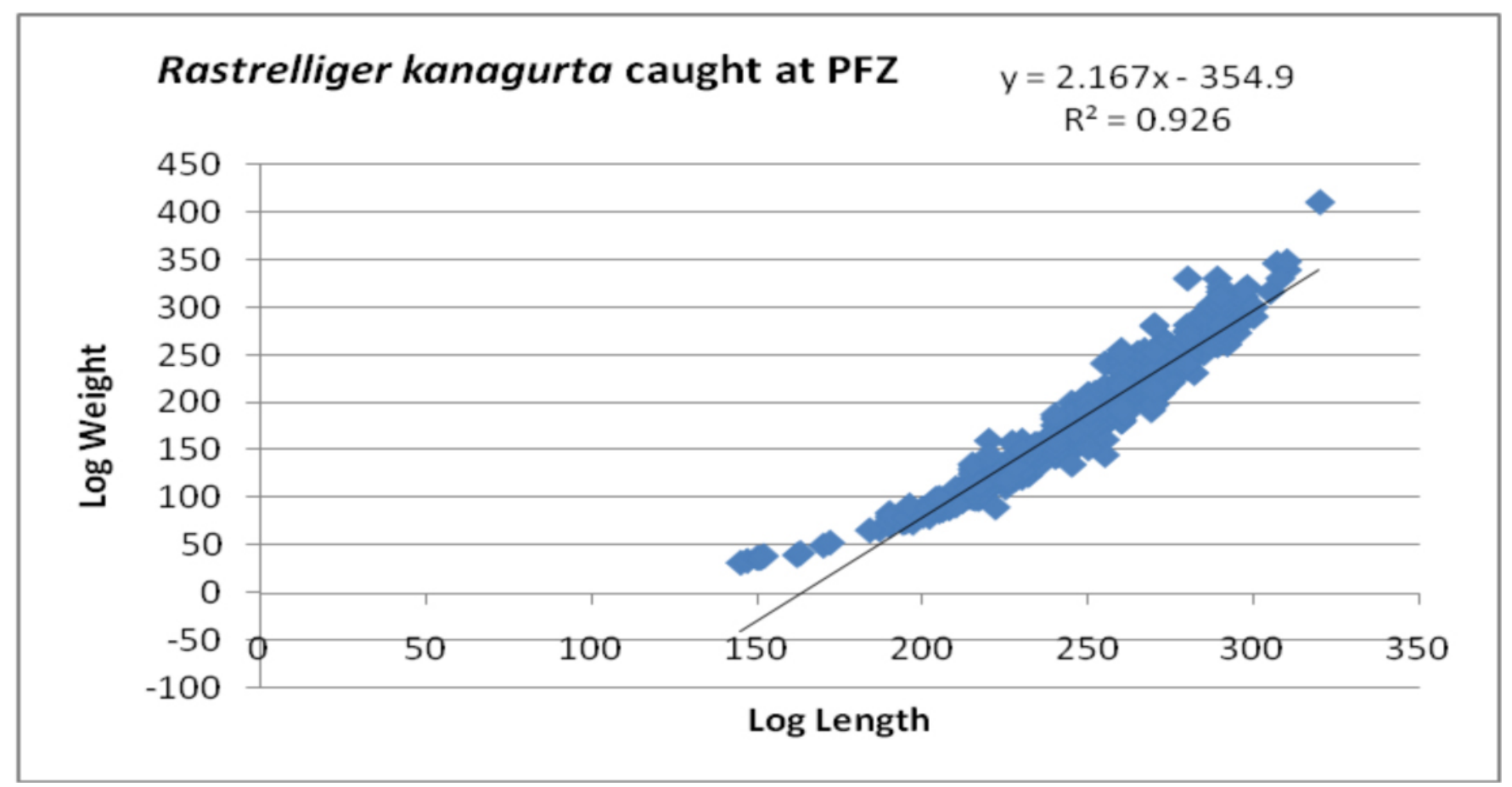

Fig. 5: Scatter diagram for $R^{2}$ value at PFZ

Fish samples $R$. kanagurta have been collected from the landing centres which were captured from PFZ and Non-PFZ of Andaman Islands and Length frequency of the fish has been carried out (Fig. 3). Altogether 9 Class Intervals with respect to length were observed i.e. 141-160 mm, 161-180mm, 181-200 mm, 201-220 mm, 221-240 mm .......301-320mm (Fig. 4). In the Class Intervals of 261-280 altogether 199 specimens have been observed contributing $30.9 \%$ in the PFZ and the Class Intervals of 201-220, 144 specimen have observed contributing to $23 \%$ of the catch from the Non-PFZ.

\section{Length weight relationship at PFZ and Non-PFZ:}

The total fish samples collected from the FLC, Junglighat which captured at PFZ and Non PFZ were 645 and 625 respectively. The length weight relationship (LWR) were illustrated for this species (Table 2), the $R^{2}$ values of $R$. kanagurta correspond to the PFZ and Non-PFZ were 0.926 and 0.893 respectively (Fig. 5 and Fig. 6). The $R^{2}$ value of the species at PFZ was higher which could be attributed to higher abundance food from the Potential Fishing Zone.

\section{Hydrographical parameters:}

The water samples have been collected from various sites of PFZ and Non-PFZ during the study period and analysed. There are differences between PFZ and Non-PFZ in Visibility using Secch Disk due to accumulation of planktons. The average visibility at PFZ and Non-PFZ were $15.49 \pm 0.28 \mathrm{~m}$ and $16.74 \pm 0.25$ respectively. The average Dissolved oxygen (DO) values at PFZ and Non-PFZ were $6.30 \pm 0.05 \mathrm{~m} / \mathrm{lit}$ and $5.95 \pm 0.06$ $\mathrm{ml} /$ lit respectively. Due to density of phytoplankton the Dissolved oxygen increased at PFZ than Non-PFZ and also due to Eddies. Alkalinity was at PFZ 111.16 \pm 1.09 $\mathrm{ml} /$ lit and Non PFZ 113.68 $\pm 1.28 \mathrm{ml} /$ lit respectively (Table - 4 ). There were variations in alkalinity between PFZ and Non-PFZ due to water current and Eddies (upwelling and down welling) more at PFZ.

The data have been collected during the visit every year. The analysis of the data were focused only to find out Landing of Rastrelliger kanagurta amongst the other pelagic fishes. There 33 validations have been carried out for the PFZ advisories in each PFZ and Non-PFZ around Andaman Islands (Table 1). Fish samples collected, caught from both PFZ and Non-PFZ and found variations in the length frequency i.e. the Class Intervals 261-280 contributing $30.9 \%$ in the PFZ and the Class Intervals of 201-220, contributing to $23 \%$ of the catch from the Non-PFZ. The variation of Length and weight relationship has been observed in both areas (Fig. 5 and Fig. 6). The $R^{2}$ value of the species at PFZ was higher which could be attributed to higher abundance food from the Potential Fishing Zone.

According to the validation the catch within the PFZ area gave more CPUE and net profit compared to the results of operations in the non PFZ areas. Fishing operations undertaken on or closer to dates on which related SST/chlorophyll imageries received, yielded positive results. When the gap increases the yield within PFZ is likely to come down unless the features remain 


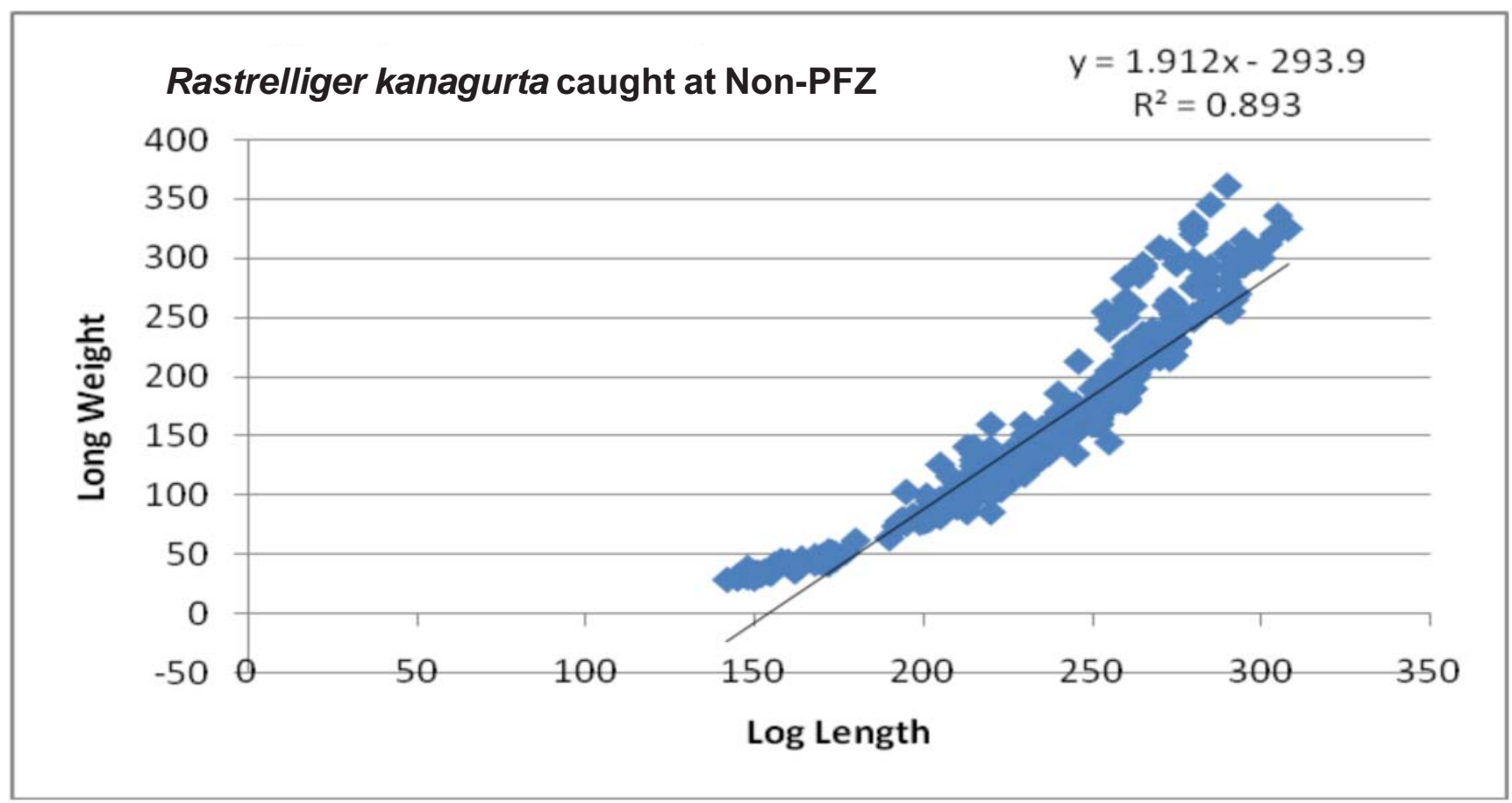

Fig. 6: Scatter diagram for $R^{2}$ value at Non-PFZ

more or less in the same location as revealed by the succeeding satellite imagery.

Mesoscale eddies enhance the productivity in a stratified coastal environment by upwelling. The seas around the Andaman and Nicobar Islands have been found to have frequent mesoscale eddy activity. Commercial fishing grounds coincide with upwelling areas associated with cyclonic and anti-cyclonic eddies and also with areas between two adjacent eddies. There are different eddy zones supporting different types of fishing gears and fish. The current study aims at identifying the different zones of mesoscale eddies in the Andaman Sea and compares the productivity and fishing activity in each of them².

\section{References}

1. Abdusammad EM, Pillai NGK, Mohammed Kasim H, Habeeb Mohamed OMMJ, Jeybalan K. Fishery biology and population characteristics of the Indian mackerel, Rastrelliger kanagurta (Cuvier) exploited along the Tuticorin coast. Indian J Fish. 2010; 57 : 17-21.

2. Anand Arura Krishnan P, Grinson George, Goutham Bharathi MP, Kaliyamoorthy M, Hareef Baba Shaeb K, Suryavanshi AS, Srinivasa Kumar T, Joshi AK. The influence of mesoscale eddies on a commercial fishery in the coastal waters of the Andaman and Nicobar Islands, India. International Journal of Remote Sensing. 2014; 35 (17): 6418-6443,

3. Annual Report. Central Marine Fisheries Research Institute, Cochin, 2012-13.

4. Anonymous. Roadmap for the development of fisheries in Andaman and Nicobar Islands. 2004; 89 p CMFRI, Kochi.

5. Asokan PK, Krishna Kumar PK, Ghosh, SG. Sea surface temperature changes and distribution shifts of Indian Mackerel (Rastrelliger kanagurta). In: Vivekanandan E et al (ed) Marine eco-system challenges and opportunities, book of abstracts.Marine Biological Association of India Cochin. 2009; 247-248

6. Beverton MA, Holt SJ. On the dynamics of exploited fish populations, U.K. Ministry of Agriculture and Fisheries. Fisheries Investigation Series. 1957; 2533.

7. Choudhury SB, Rao KH, Rao MV. Satellite remote sensing for marine resources assessment. Trop. Ecol. 2002; 43(1): 187-202 
8. CMFRI. Marine fish landings in India. Technical report, CMFRI, FRAD, Kochi. 2014.

9. Dam Roy S, Grinson George. "Marine Resources of Islands: Status and Approaches for sustainable Exploitation I Conservation with Special Emphasis to Andaman and Nicobar", Indian Journal of Animal Sciences. 2010; 80 (4) : 57-62.

10. Desai PS, Honnegowda H, Kasturirangan. Ocean research in India: Perspective from space. Curr. Sci. 2000; 78 (3) : 268-278.

11. Devaraj M, Kurup KN, Pillai NGK, Balan K Vivekanandan, R sathiadas R. Status, prospects and management of small pelagic fisheries in India. In: Devaraj,M. and P. Martosubroto (Eds.) Small Pelagic Resources and their Fisheries in the Asia-Pacific region. Proc., APFIC Working Party on Marine Fisheries, Bangkok, Thailand, RAP Publn. 1997; 31: 91 - 197.

12. Dwivedi RM, Solanki HU, Nayak SR, Gulati DK, Somvanshi VS. Exploration of fishery resources through integration of ocean colour with sea surface temperature: Indian experience. Ind. J. Mar. Sci. 2005; 34(4): 430-440.

13. FSI. "National Marine Fisheries Census 2005: Union Territories of Andaman \& Nicobar and Lakshadweep Islands." New Delhi: Ministry of Agriculture, Department of Animal Husbandry, Dairying \& Fisheries, Government of India. $2007 ; 177$.

14. Gnanamuttu JC. On the occurrence of Rastrelliger faughni Matsui In the Indian waters. Indian Journal of Fisheries. 1971; 18 (1 \& 2) : 170-173.

15. Goutham J, Mohanraju R. Some aspects of mackerel diversity and Morphometric Studies of Rastrelliger genera from Port Blair Andamanwaters. International Journal of Fisheries and Aquatic Studies. 2015; 3 (1): 196-198.

16. Grinson George, Pandian Krishnan, Sibnarayan Dam Roy, Kamal Sarma, Goutham Bharathi, MP, Kaliyamoorthy, M, Krishnamurthy V, Srinivasa Kumar T. Validation of Potential Fishing Zone (PFZ) Forecasts from Andaman and Nicobar Islands: Fishery Technology. 2013; 50: 208 - 212.

17. John ME, Bhargava AK, Varghese S, Gulati DK, Ashok SK, Dwivedi SK. "Fishery Resources of the Indian EEZ around Andaman and Nicobar Islands" Bulletin of Fishery Survey of India. 2005; 25 : 16-38.

18. Jones S, Silas EG. Mackerel from the Andaman Sea. Proc. Symposium on Scombroid Fishes, Pt. I: 255- 282. Mar. biol. Ass. India. 1962.

19. Madhu K. Rema Madhu, Ahlawat, SPS, Raveendran EK, Dam Roy S. Status of exploitation of tuna, mackerel and seer fish in Andaman and Nicobar Islands. In the book Management of Scombroid Fisheries Edited by N.G.K. Pillai, N.G. Menon, P.P. Pillai, U. Ganga, CMFRI, Kochi, India. 1999.

20. Mir FA, Mir JI, Patiyal RS, Kumar P. Length-weight relationships of four snowtrout species from the Kashmir Valley in India. Journal of Applied Ichthyology. 2014; 30 (5): 1103-1104. doi:10.1111/jai.12482.

21. Mohammed Tahir. Present status and future scope of fisheries in the Andaman group of islands. Journal of the Indian Fisheries Association. 1988; 18 : 189-195.

22. Nayak SR, Solanki HU, Dwivedi RM. Utilization of IRS P4 ocean colour data for potentialfishing zone-A cost benefit analysis. Ind. J. Mar. Sci. 2003; 32(3): 244-248

23. NCAER. Impact assessment and economic benefits of weather and marine services, $104 \mathrm{p}$, National Council of Applied Economic Research, New Delhi. 2010.

24. Petrakis G, Stergiou KI. Weight-length relationships for 33 fish species in Greek waters. Fisheries Research.1995; 21: 465-469. doi: 10.1016/0165-7836(94)00294-7.

25. Solanki HU, Dwivedi RM, Nayak SR, Naik SK, John ME, Somvanshi VS. "Application of Remotely Sensed Closely Coupled Biological and Physical Processes for Marine Fishery Resources Exploration." International Journal of Remote Sensing. 2005; 26 : 2029-2034.

26. Solanki HU, Dwivedi RM, Nayak SR. Synergistic analysis of Sea WiFS chlorophyll concentration and NOAAAVHRR SST features for exploring marine living resources. Int. J. Rem. Sen. 2001; 22: 3877-3882 
27. Solanki HU, Dwivedi RM, Nayak SR, Gulati DK, John ME, Somavanshi VS. Potential Fishing Zone (PFZs) forecast using satellite data derived biological and physical processes. J. Ind. Soci. Rem. Sen. 2003; 31 (2) : 67-69

28. Solanki HU, Pradhan Y, Dwivedi RM, Nayak SR, Gulati DK, Somvanshi VS. Application of Quick SCAT Sea Winds data to improve remotely sensed Potential Fishing Zones (PFZs) forecast methodology: Preliminary validation results. Ind. J. Mar. Sci. 2005; 34 (4): 441-448

29. Solanki HU, Raman M, Kumari B, Dwivedi RM, Narain A. Seasonal trends in the fishery resources off Gujarat: salient observations using NOAA-AVHRR. Ind. J. Mar. Sci. 1998; 27: 438-44

30. Teixeira De Mello F, Iglesias C, Borthagaray AI, Mazzco N, Vilches J, Larrea D, Ballabio R. Ontogenicallometric coefficient changes. Implications of diet shift and morphometric attributes in Hoplias malabaricus (Bloch) (Characiforme, Erythrinidae). Journal of Fish Biology. 2006; 69 : 1770-1778.

31. Thomas J, Venus S, Kurup BM. Length- weight relationship of some deep-sea fish inhabiting continental slope beyond 250m depth along West coast of India. Naga. World Fish Center Quarterly. 2003; 26 : 17-21.

32. Vivekanandan E, Gomathy S, Thirumilu P, Meiyappan MM, Balakumar SK. Trophic level of fishes occurring along the Indian coast. J. Mar. Biol. Ass. India. 2009; 51 (1): 44 - 51.

33. Yohannan TM, Sivadas M. Indian mackerel, In: Status of exploited marine fishery resources of India (Modayil, M.M. and Jayaprakash, A.A., Eds.), p. 60-65, Central Marine Fisheries Research Institute, Cochin. 2003; 308. 